\title{
Influence of Peer Pressure and Self-Efficacy for Alcohol Self-Regulation on Chinese University Physical Education Students' Drinking Behaviors
}

\author{
Lanyan Ding1, Ian M. Newman ${ }^{1 *}$, Eric S. Buhs ${ }^{2}$, Duane F. Shell1 \\ ${ }^{1}$ Nebraska Prevention Center for Alcohol and Drug Abuse, Department of Educational Psychology, University of \\ Nebraska-Lincoln, Lincoln, NE, USA \\ ${ }^{2}$ Department of Educational Psychology, University of Nebraska-Lincoln, Lincoln, NE, USA \\ Email: *inewman1@unl.edu
}

How to cite this paper: Ding, L. Y., Newman, I. M., Buhs, E. S., \& Shell, D. F. (2018). Influence of Peer Pressure and Self-Efficacy for Alcohol Self-Regulation on Chinese University Physical Education Students' Drinking Behaviors. Advances in Physical Education, 8, 46-57.

https://doi.org/10.4236/ape.2018.81006

Received: November 15, 2017

Accepted: February 8, 2018

Published: February 11, 2018

Copyright $\odot 2018$ by authors and Scientific Research Publishing Inc. This work is licensed under the Creative Commons Attribution International License (CC BY 4.0).

http://creativecommons.org/licenses/by/4.0/

\begin{abstract}
This study examined peer group influence on university student drinking in China and the indirect effects of peer pressure and self-efficacy for alcohol self-regulation. A total of 951 undergraduate university students (first, second and third year) from a university in central China completed questionnaires asking about perceived peer pressures, self-efficacy for alcohol self-regulation, and drinking frequency. Analysis of their answers showed that the drinking frequency among physical education (PE) students was higher than among the comparison group (History students). The PE students perceived greater peer pressure, and had lower self-efficacy for alcohol self-regulation, both of which contributed directly to drinking frequency. Path analysis indicated indirect effects of peer pressure and self-efficacy for alcohol self-regulation on the association between peer group membership and drinking frequency. This suggested that skills training to increase self-efficacy for alcohol self-regulation in culturally-specific settings have the potential to both directly and indirectly lower drinking rates in peer groups with high peer pressure and higher than normal drinking.
\end{abstract}

\section{Keywords}

Peer Group, Peer Pressure, Self-Efficacy for Alcohol Self-Regulation, Alcohol Use, China, University Student

\section{Introduction}

In China, moderate drinking with other people is considered a way of showing 
respect and facilitating interpersonal communication (Lu, Engs, \& Hanson, 1997). Most people are introduced to alcohol at a young age, and those who go to university generally began drinking with friends at that time (Leng, 2009). The main reasons they gave for drinking were socializing, making friends, and acting "cool" (e.g., Wu et al., 2009), while the main drinking occasions are annual festivals, birthday parties, and other social situations (Zhang \& Liu, 2008). These studies suggested that drinkers more frequently give social reasons for drinking than physical gratification reasons for drinking. Implicit in the character of social drinking is the influence of peer pressure on alcohol use.

This study was designed to confirm or refute reports by Chinese university officials responsible for student counseling and supervision that students in the physical education discipline are more often involved in discipline and behavior infractions than students in other disciplines. This conclusion is supported by Dong et al. (2006) and Tu (2007). We surmised that this was the result of the relationship between student peer group membership, their perceptions of peer pressure, which in turn was related to alcohol consumption. The outcome of these relationships was dependent on self-efficacy for alcohol self-regulation.

\subsection{Peer Group}

As students enter university, they spend more time with peers. Fitting into a group and developing social networks become a necessary developmental task (Santor, Messervey, \& Kusumakar, 2000). Identifying with a group membership strengthens students' self-identity, feeling of self-worth and benefits their social acceptance (Regan \& Morrison, 2011). In this situation, they are likely to imitate normative behaviors within a group and conform to a group norm. Their attitudes and behaviors about substance use (i.e., alcohol consumption) are increasingly similar to people who are friends in the group (Mukama, 2010; Burk, Van Der Vorst, Kerr, \& Stattin, 2011). Studies have consistently indicated the peer group membership influences personal alcohol use among adolescents (e.g., Korte, Pieterse, Postel, \& Van Hoof, 2012).

Physical education students, like students in all academic fields, are expected to master the knowledge content of their field. In addition, physical education students have the additional expectation that they develop physical skills. While skill development is a part of some other disciplines, physical education students experience skill development in a competitive situation, creating a special bond between group members. Membership in groups can increase a students' perception of peer pressure.

\subsection{Peer Pressure}

The influence of peer group on alcohol consumption is, to a large extent, achieved through peer pressure, which is considered as the "price of group membership" (Clasen \& Brown, 1985). Peer pressure that accompanies peer group membership refers to a subjective feeling of being pushed, urged, or dared 
by others to do something only because of the expectations of other people (Santor et al., 2000). Examples of alcohol-related peer pressure in the context of Chinese university student life include being offered a toast, having a drink refilled without asking, being teased for refusing to drink, being urged to drink more, or buying rounds. Drinking within a group is not an individual choice, but rather an obligation to group harmony and a loyalty to others within the group (Borsari \& Carey, 2001; Santor et al., 2000).

While there is considerable literature describing peer pressure and alcohol use among Western students (see Borsari \& Carey, 2001 for a review), the Chinese literature about Chinese college students peer pressure is limited. Leng and her colleagues noted that almost half of the students in their study (43.4\%) initiated their alcohol drinking due to persuasion from friends (Leng, Jia, Yan, Wang, Zhang, \& Wang, 2009). Similarly, Ma and Fan (2000) reported that the drinking behaviors of college students frequently predicted drinking amount and frequency of their friends.

\subsection{Self-Efficacy for Alcohol Self-Regulation}

Self-efficacy for self-regulation refers to a person's confidence in their own ability to manage a behavior. In this study we are concerned specifically with alcohol self-regulation; that is, the behaviors used to manage drinking amount, drink responsibly, and resist or refuse alcohol (Annis, 1982; Baldwin, Oei, \& Young, 1993; Bandura, 2004; DiClemente, Carbonari, Montgomery, \& Hughes, 1994; Ellickson \& Hays, 1991; Webb \& Baer, 1995). Self-efficacy for alcohol self-regulation is a person's confidence that he or she can effectively enact these self-regulation behaviors (DiClemente et al., 1994; Shell, Newman, \& Fang, 2010). Studies have consistently shown that students with higher self-efficacy for alcohol self-regulation are more able to regulate their drinking behaviors and thus drink responsibly in clinical samples (Webb \& Baer, 1995), western populations (Young, Connor, Ricciardelli, \& Saunders, 2006), and Chinese populations (Shell et al., 2010; Yeh \& Chen, 2007).

As Bandura (1977) points out an individual's perceived self-efficacy for alcohol use is affected by a number of factors. For example, drinking values and behaviors within a group impact a person's confidence to manage their own drinking behaviors. A more favorable belief about alcohol within a group reduces self-efficacy for self-regulating drinking behaviors, because a person does not want to go against the majority belief within a group. Adopting the group's drinking belief is a way to maintain group membership. Active drinking offers or toasts from peers impact students' beliefs in their efficacy to regulate their own drinking. An individuals' self-efficacy to say "no" to alcohol offers may depend on a failure to learn or plan ways to say no.

The purpose of this study was to test the hypothesis that peer group membership is related to drinking frequency and this relationship is indirectly affected by peer pressure and self-efficacy for alcohol self-regulation. The relationships are illustrated in Figure 1. 


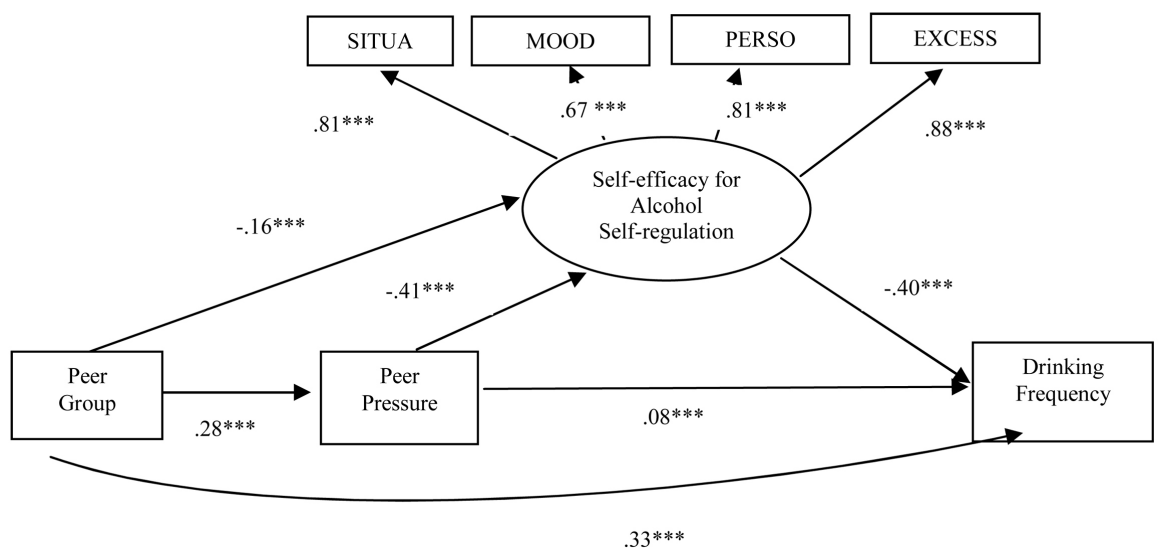

Figure 1. Path model predicting the relationship among peer groups, peer pressure, self-efficacy for alcohol self-regulation and drinking frequency. ${ }^{* *} \mathrm{p}<.001$. SITUA $=$ situational social pressures, $\mathrm{MOOD}=\operatorname{mood} / \mathrm{affect}, \mathrm{PERSO}=$ personal social pressures, and EXCESS $=$ excessive drinking.

\section{Methods}

\subsection{Subjects}

An invitation letter describing the study was sent to all students enrolled as History majors $(\mathrm{HIST}=432)$ and all students enrolled as Physical Educational majors $(\mathrm{PE}=519)$ at a major university in central China: a total of 951 students. This university serves students from all parts of China. Data were collected from all students present in the surveyed classrooms in June 2014. Complete data were obtained from 891 students (93.7\%): 450 females (50.5\%), 441 males (49.5\%); 293 freshmen (32.9\%), 336 sophomores (37.7\%), and 262 juniors (29.4\%); majoring in HIST $(\mathrm{N}=404$, males $=91$, females $=313)$ or $\mathrm{PE}(\mathrm{N}=487$, males $=$ 359 , females $=128$ ). The ages in this sample ranged from 19 to 23 years old.

\subsection{Measures}

Drinking frequency. Drinking frequency measures were based on reported frequency in the past year and the past month. Subjects were grouped into three ordinal categories: 1) non-drinkers (those who reported never drinking or not drinking within the past year), 2) occasional drinkers (those who drank in the last year but not in the last 30 days), and 3) regular drinkers (those who drank within the last 30 days). While these categories allow possible misclassification, this occurs only occasionally. This classification has been used widely in studies of drinking in China (Shell et al., 2010; Tang et al. 2013; Newman et al., 2013; Newman, Huang, Shell \& Qian, 2014; Newman, Qian, Shell, Qu, \& Zhang, 2006; Zhang, Merrick, Newman, \& Qian, 2007). Attempts to refine these drinking measures by adding quantity questions have not been productive because Chinese drinking involves different size drinking cups, nonstandardized beverage containers, and beverage alcohols with a wide range of strength (alcohol by volume), all of which confound estimates of alcohol quantity (see Newman, Qian, \& Xue, 2004, for a review). 
Perceived Peer Pressure. The perception of peer pressure among Chinese university students was measured by an eight-item scale adapted from the scale developed by Santor et al. (2000). Students rated each item on a five-point Likert scale $(1=$ strongly disagree, $2=$ mildly disagree, $3=$ neither agree nor disagree, $4=$ mildly agree, $5=$ strongly agree). For each student, an average score from all eight items was used to indicate perceived peer pressure. An average score of five indicated the strongest perception of peer pressure promoting alcohol use, while the score of one indicated the lowest perceived peer pressure for alcohol consumption. Cronbach's alpha for the original scale was 0.91 (Santor et al., 2000) and for the adapted scale used in this study was .83. The mean score was 2.9 , and the standard deviation .77 .

Chinese Alcohol Self-Regulation Self-efficacy (CASSE). Students' self-efficacy for resisting pressure from peers was measured using the Chinese Alcohol Self-Regulation Self-efficacy (CASSE) scale (Qian, Hu, Newman, \& Hou, 2008; Shell et al., 2010; Newman, Huang, Shell, \& Qian, 2014). The CASSE contained 28 items scored on a $0-100$ scale. For each item students selected the number that best reflected their confidence. A score of 100 represented full confidence to resist the pressure to drink, a score of zero represented no confidence. The CASSE includes four subscales for confidence to regulate one's own drinking: eight items for situational social pressures (e.g. resist pressure to drink on a date), four items for mood/affect (e.g. resist the urge to drink when feeling joyful/sad), eight items for excessive drinking (e.g. resist pressure to get drunk at a birthday party) and eight items for personal social pressures (e.g. resist the urge to drink to impress friends). The Cronbach's alphas for the original subscale were .90 for situational social pressures, .80 for mood/affect, .92 for excessive drinking and .91 for personal social pressures (Shell et al., 2010). For this sample the alpha was .90 for situational social pressures $(M=60.0, S D=23.37), .81$ for $\operatorname{mood} /$ affect $(\mathrm{M}=76.67, \mathrm{SD}=21.86), .88$ for excessive drinking $(\mathrm{M}=75.85, \mathrm{SD}=$ $20.09)$ and .90 for personal social pressures $(M=75.75, S D=19.69)$.

Demographic characteristics. Students answered three demographic questions about gender, year in school, and academic major.

\subsection{Data Analysis}

To examine the relationships of peer group membership, perceived peer pressure, self-efficacy for alcohol self-regulation, and drinking frequency, SPSS 22.0 and Mplus 7.0 were used. SPSS 22.0 was used for the item analysis for peer pressure measurement. Mplus 7.0 was used for the factor analysis for peer pressure measurement and self-efficacy for alcohol self-regulation. A path model was used to assess the relationship among peer group membership, peer pressure, self-efficacy for alcohol self-regulation, and drinking frequency.

\subsection{Ethical Considerations}

Approval was obtained prior to data collection from authorities of the Chinese 
university and from the Institutional Review Board of the University of Nebraska-Lincoln (IRB Approval \#: 20140213516EX). The researchers applied for and received a waiver of the consent process. The anonymity of the student participants and confidentiality of their survey answers was guaranteed. The survey questions asked only about legal and public behaviors.

\section{Results}

After the text edit has been completed, the paper is ready for the template. Duplicate the template file by using the Save As command, and use the naming convention prescribed by your journal for the name of your paper. In this newly created file, highlight all of the contents and import your prepared text file. You are now ready to style your paper.

\subsection{Peer Pressure and Self-Efficacy for Alcohol Self-Regulation by Peer Groups}

Table 1 shows that PE students perceived significantly higher peer pressure for alcohol use than History students $(p<.001)$. There were significant differences in self-efficacy for alcohol self-regulation between the two peer groups. History students scored higher on each subscale of the CASSE, indicating a greater sense of self-efficacy for alcohol self-regulation than PE students $(p<.001)$.

\subsection{Drinking Status by Peer Group}

There were no significant differences in drinking status by year in school within the two disciplines (PE sample $\chi^{2}(4)=11.01, p=.06$; HIST $\chi^{2}(4)=4.73, p=.32$ ). There were significantly more regular drinkers among PE students $(77.8 \%)$ than history students (39.9\%) and significantly more males in the PE sample than the history sample (Table 2). Accordingly we compared our model with an alternative

Table 1. Peer pressure and self-efficacy for alcohol self-regulation by peer group.

\begin{tabular}{|c|c|c|c|c|c|}
\hline & & \multicolumn{2}{|c|}{$\mathrm{PE}$} & \multicolumn{2}{|c|}{ HIST } \\
\hline & & Mean & $S D$ & Mean & $S D$ \\
\hline \multirow{3}{*}{$\begin{array}{l}\text { Perceived Peer } \\
\text { Pressure }\end{array}$} & & 3.10 & .73 & 2.66 & .77 \\
\hline & \multicolumn{5}{|c|}{$t(802)=-8.27 p<.001$} \\
\hline & Situational pressure & 53.82 & 22.05 & 67.63 & 22.72 \\
\hline \multirow{7}{*}{$\begin{array}{l}\text { Self-Efficacy for } \\
\text { Alcohol } \\
\text { Self-Regulation }\end{array}$} & \multicolumn{5}{|c|}{$t(860)=9.02 p<.001$} \\
\hline & Mood/affect & 73.45 & 22.82 & 80.66 & 19.92 \\
\hline & $t(862)=4.89 p<.001$ & & & & \\
\hline & Excessive drinking & 71.57 & 20.95 & 81.12 & 17.63 \\
\hline & $t(864)=7.15 p<.001$ & & & & \\
\hline & Personal social pressure & 72.60 & 20.41 & 79.63 & 18.06 \\
\hline & $t(861)=5.30 p<.001$ & & & & \\
\hline
\end{tabular}

Notes: Perceived peer pressure items scored from 1 (low perceived pressure) to 5 (high perceived pressure). Self-efficacy for Alcohol Self-Regulation scored from 100 (absolutely confident) to 0 (not at all confident). 
Table 2. Drinking status by peer group and gender.

\begin{tabular}{|c|c|c|c|c|c|c|c|c|c|c|c|c|}
\hline & \multicolumn{4}{|c|}{$\mathrm{PE}$} & \multicolumn{4}{|c|}{ HIST } & \multicolumn{4}{|c|}{ Total } \\
\hline & \multicolumn{2}{|c|}{ M } & \multicolumn{2}{|c|}{$\mathrm{F}$} & \multicolumn{2}{|c|}{ M } & \multicolumn{2}{|c|}{$\mathrm{F}$} & \multicolumn{2}{|c|}{ M } & \multicolumn{2}{|c|}{$\mathrm{F}$} \\
\hline & $n$ & $\%$ & $n$ & $\%$ & $n$ & $\%$ & $n$ & $\%$ & $n$ & $\%$ & $n$ & $\%$ \\
\hline Regular Drinker & 311 & 86.6 & 68 & 53.1 & 53 & 58.2 & 108 & 34.5 & 364 & 80.9 & 176 & 39.9 \\
\hline Occasional Drinker & 38 & 10.6 & 40 & 31.3 & 29 & 31.9 & 93 & 29.7 & 67 & 14.9 & 133 & 30.2 \\
\hline Non-drinker & 10 & 2.8 & 20 & 15.6 & 9 & 9.9 & 112 & 35.8 & 19 & 4.2 & 132 & 29.9 \\
\hline Total & 359 & 100 & 128 & 100 & 91 & 100 & 313 & 100 & 450 & 100 & 441 & 100 \\
\hline
\end{tabular}

Note: $\mathrm{PE}=$ Physical Education students, $\mathrm{HIST}=$ History students. $\mathrm{M}=$ Male, $\mathrm{F}=$ Female.

model using a multiple group analysis to test if path coefficients were different across the male and the female groups. Results indicated no significant difference in model fit between the multiple group model and the ungrouped model $\left(\Delta \chi^{2}(17)=14.24, p>.05\right)$. Based on the parsimonious principle, we chose to use the ungrouped model (Grünwald, 2000).

\subsection{Path Analysis}

A path analysis, using Mplus 7.0, estimated the relationships among peer group membership, peer pressure, self-efficacy for alcohol self-regulation, and drinking frequency. The outcome variable of drinking frequency was treated as a categorical variable including non-drinkers, occasional drinkers, and regular drinkers. These three categories were treated as ordinal as it was hypothesized that there was an inherent ordering from non-drinking to occasional drinking and then to regular drinking. Peer group was a dummy coded exogenous variable $(0=$ History student; 1 = PE student). The exogenous variable peer pressure was entered as the peer pressure scale score. Self-efficacy for alcohol self-regulation was entered as a latent variable using the four CASSE sub-scale scores (coefficients shown in Figure 1).

The path model was tested with Mplus 7.0 using the weighted least squares means and variance adjusted (WLSMV) estimators. The fit indices suggested adequate model fit $(\mathrm{CFI}=.93, R M S E A=.097, W R M R=.97)(\mathrm{Yu}, 2002)$. The overall explained variances $\left(R^{2}\right)$ for each predicted variable in the path model were drinking $=.39$, peer pressure $=.08$, self-regulation self-efficacy $=.23$.

\subsection{Role of Peer Group Membership, Peer Pressure, and Self-Efficacy for Alcohol Self-Regulation in Predicting Drinking}

Direct effects. As shown in Figure 1, peer group (being a PE major) significantly predicted increased drinking frequency, higher peer pressure, and lower self-efficacy for alcohol self-regulation. Higher perceived peer pressure was associated with an increased drinking frequency and with lower self-efficacy for alcohol self-regulation. Higher self-efficacy for alcohol self-regulation predicted decreased drinking frequency. 
Indirect effects. Mplus 7.0 was used to estimate indirect effects within the model in Figure 1. Being in the PE peer group had an indirect effect increasing drinking through increasing peer pressure, and decreasing self-efficacy for alcohol self-regulation (standardized coefficient $=.05, p<.001$ ). Higher peer pressure had an indirect effect increasing drinking through decreasing self-efficacy for alcohol self-regulation (standardized coefficient $=.16, p<.001$ ). Finally, being in the PE peer group had an indirect effect on decreasing self-efficacy for alcohol self-regulation through increasing peer pressure (standardized coefficient $=$ $-.012, p<.001)$.

Summary of effects. In summary, higher self-efficacy for alcohol self-regulation directly lowered drinking. Higher peer pressure increased drinking directly. Higher peer pressure also increased drinking indirectly by lowering self-efficacy for alcohol self-regulation. Being in the PE peer group increased drinking directly and also indirectly by lowering self-efficacy for alcohol self-regulation and by increasing peer pressure to drink, which in turn also lowered self-efficacy for alcohol self-regulation.

\section{Discussion}

Results from path analysis confirmed our hypothesis that peer group membership is directly related to alcohol drinking frequency among Chinese university students and this relationship is indirectly affected by peer pressure and self-efficacy for alcohol self-regulation.

1) Direct and indirect effects of peer group. Our path analysis indicated higher drinking rates among PE students compared to History students at the same university. This answers the initial question that prompted this project: that PE students, as a discipline, had higher drinking rates as suggested to us in anecdotal reports and as reported by Dong et al. (2006) and Tu (2007).

The hypothesized relationship between the peer group membership and alcohol drinking frequency is indirectly affected by peer pressure and self-efficacy for alcohol self-regulation. Specifically, our results show higher perceived peer pressure and lower self-efficacy for alcohol self-regulation among PE students, confirming our hypothesis that peer pressure has an indirect effect on the association between peer group and drinking frequency. This finding has been reported by others (e.g., Lo, 1995). Our results also confirmed our hypothesis about the indirect effect of self-efficacy for alcohol self-regulation on the relationship between peer group and drinking frequency. This finding has important implications for education and prevention programs. Knowing about the relationship between a group of students and their drinking behaviors and understanding the importance of indirect variables would support the development of more focused educational initiatives, perhaps overcoming the criticism of Oei and Morawska (2004) who reported that the failure of many programs is due to poor specificity and design.

2) Direct effects of peer pressure. Results indicated that higher peer pressure 
increased drinking frequency directly. In Chinese culture, drinking is less often done for self-gratification and more often done as a means of establishing, reinforcing or enhancing relationships. The etiquette surrounding social occasions requires one to drink with and toast others to affirm friendships, celebrate life's successes, or cement business deals. This favorable belief toward to alcohol and the reciprocal expectations reinforce peer pressures to drink. Our findings suggest the need to know more about culturally-specific peer pressures. Understanding the nature of this peer pressure is basic to developing educational programs that could teach social skills to resist peer pressures to drink without fracturing important relationships. Newman et al. (2017) have suggested this might be possible in certain drinking situations with certain groups of peers, and that it might be possible to exploit the positive influence of peers to maintain safe drinking behaviors and discouraging risky health behaviors.

3) Indirect effects of peer pressure on drinking through self-efficacy for alcohol self-regulation. Our findings confirmed that higher self-efficacy for alcohol self-regulation directly lowered drinking frequency, consistent to previous findings (e.g., Shell et al., 2010). Importantly, findings advance our understanding of the cognitive mechanism underlying the association between peer pressure and drinking. Higher peer pressure lowered self-efficacy for alcohol self-regulation, which in turn increased drinking frequency. The indirect role of self-efficacy for alcohol self-regulation in the relationship of peer pressure to drinking behaviors suggests an opportunity to use both social environment and personal self-efficacy to regulate alcohol use. This finding reflects Bandura's (1986) social cognitive theory that learning is the result of the integrative effects of environmental factors, person's cognitive mechanism, and behavioral consequences. Educational programs targeting any one factor will be less effective. In the context of the socially motivated and etiquette-bound drinking culture in China, any educational program directed at reducing risky drinking behaviors will need to focus both on teaching restraint to persons doing the pressuring as well as teaching self-regulatory skills to the persons being pressured.

\section{Summary}

We hypothesized that peer group membership was related to students' drinking frequency, and this relationship was indirectly affected by peer pressure and self-efficacy for alcohol self-regulation in a Chinese undergraduate university student sample. Results from a path model confirmed our hypotheses. Students in the PE group reported higher peer pressure and lower self-efficacy for alcohol self-regulation, leading to increased drinking frequency. Results also indicated that higher peer pressure increased drinking frequency directly and also increased drinking frequency indirectly by lowering self-efficacy for alcohol self-regulation. Those planning educational programs to reduce risky drinking would benefit from a better understanding of the role of group characteristics, peer influences, and personal cognitive mechanisms like self-efficacy. 


\section{Limitations}

This study is limited to students studying in two disciplines in one large university in China. Samples from a larger number of geographically diverse institutions are needed. This study is based on cross-sectional and self-reported data only. Self-report surveys are subject to bias. Students may have inaccurately represented the nature of their responses to overt peer influences. Nevertheless, findings on peer pressure and drinking were similar to findings in other studies, and the identification of self-efficacy for alcohol self-regulation as having both a direct and indirect effect on drinking suggests an option for interventions to reduce risk.

\section{References}

Annis, H. M. (1982). The Situational Confidence Questionnaire (SCQ-39). Toronto, ON: Addiction Research Foundation.

Baldwin A. R., Oei T. P. S., \& Young R. (1993). To Drink or Not to Drink: The Differential Role of Alcohol Expectancies and Drinking Refusal Self-Efficacy in Quantity and Frequency of Alcohol Consumption. Cognitive Therapy and Research, 17, 511-530. https://doi.org/10.1007/BF01176076

Bandura, A. (1977). Self-Efficacy: Toward a Unifying Theory of Behavioral Change. Psychological Review, 84, 191-215. https://doi.org/10.1037/0033-295X.84.2.191

Bandura, A. (1986). Social Foundations of Thought and Action: A Social Cognitive Theory. Upper Saddle River, NJ: Prentice Hall.

Bandura, A. (2004). Health Promotion by Social Cognitive Means. Health Education \& Behavior, 31, 143-164. https://doi.org/10.1177/1090198104263660

Borsari, B., \& Carey, K. B. (2001). Peer Influences on College Drinking: A Review of the Research. Journal of Substance Abuse, 13, 391-424. https://doi.org/10.1016/S0899-3289(01)00098-0

Burk, W. J. W., Van Der Vorst, H., Kerr, M., \& Stattin, H. (2011). Alcohol Use and Friendship Dynamics: Selection and Socialization in Early-, Middle-, and Late-Adolescent Peer Networks. Journal of Studies on Alcohol and Drugs, 73, 89-98. https://doi.org/10.15288/jsad.2012.73.89

Clasen, D. R., \& Brown, B. B. (1985). The Multidimensionality of Peer Pressure in Adolescence. Journal of Youth and Adolescence, 14, 451-468. https://doi.org/10.1007/BF02139520

DiClemente, C. C., Carbonari, J. P., Montgomery, R. P. G., \& Hughes, S. O. (1994). The Alcohol Abstinence Self-Efficacy Scale. Journal of Studies on Alcohol and Drugs, 55, 141-148. https://doi.org/10.15288/jsa.1994.55.141

Dong, Y., Gao, B., Zi, L., Yang, Y., An, J., Wu, G., \& Yang, Y. (2006). Risk Health Behaviors in Physical Education Major in Dalian. China Journal School Health, 27, 337-338. (In Chinese)

Ellickson, P. L., \& Hays, R. D. (1991). Beliefs about Resistance Self-Efficacy and Drug Prevalence: Do They Really Affect Drug Use? International Journal of Addiction, 25, 1353-1378. https://doi.org/10.3109/10826089009068468

Grünwald, P. (2000). Model Selection Based on Minimum Description Length. Journal of Mathematical Psychology, 44, 133-152. https://doi.org/10.1006/jmps.1999.1280

Korte, J., Pieterse, M. E., Postel, M. G., \& Van Hoof, J. J. (2012). Private Peer Group Set- 
tings as an Environmental Determinant of Alcohol Use in Dutch Adolescents: Results from a Representative Survey in the Region of Twente. Health \& Place, 18, 892-897. https://doi.org/10.1016/j.healthplace.2012.02.010

Leng, Q. (2009). Study on Behavior, Expectation and Recognition of Drinking Alcohol and Their Related Factors of College Students in Yantai. MA Thesis, Jinan: Shandong University. http://max.book118.com/html/2014/0301/6208048.shtm

Leng, Q., Jia, C., Yan, X., Wang, Y., Zhang, J., \& Wang, Z. (2009). Investigation on Status of Alcohol Use in College Students in Yantai 2008. Prevention Medicine Tribune, 15, 135-136.

Lo, C. C. (1995). Gender Differences in Collegiate Alcohol Abuse. Journal of Drug Issues, 25, 817-836. https://doi.org/10.1177/002204269502500411

Lu, Z.-P., Engs, R. C., \& Hanson, D. J. (1997). Research Note: The Drinking Behaviors of a Sample of University Students in Nanning, Guangxi Province, People's Republic of China. Substance Use \& Misuse, 32, 495-506. https://doi.org/10.3109/10826089709039368

Ma, S., \& Fan, C. (2000). A Study on Alcohol Drinking Patterns and Reasons in College Students. Modern Preventive Medicine, 27, 56-58.

Mukama, E. (2010). Peer Group Influence, Alcohol Consumption, and Secondary School Students' Attitudes towards School. PhD Thesis, Kampala: Makerere University.

Newman, I. M., Ding, L., Shell, D. F., \& Lin, L. (2017). How Social Reactions to Alcohol-Related Facial Flushing Are Affected by Gender, Relationship, and Drinking Purposes: Implications for Education to Reduce Aerodigestive Cancer Risks. International Journal of Environmental Research and Public Health, 14, 622-633.

https://doi.org/10.3390/ijerph14060622

Newman, I. M., Huang, Z. Q., Shell, D. F., \& Qian, L. (2014). Survey of the Drinking Patterns of University Students. Chinese Journal of Social Medicine, 31, 105-108.

Newman, I. M., Jinnai, I., Zhao, J., Huang, Z., Pu, J., \& Qian, L. (2013). Social Meaning of Alcohol-Related Flushing among University Students in China. Asia Pacific Journal of Public Health, 25, 409-419. https://doi.org/10.1177/1010539511420702

Newman, I. M., Qian, L., \& Xue, J. P. (2004). College Student Alcohol Surveys: The Need for Uniform Questions. Chinese Journal of Drug Abuse Prevention and Treatment, 10, 272-275.

Newman, I., Qian, L., Shell, D., Qu, M., \& Zhang, Y. (2006). Development of Chinese Adolescents Alcohol Expectancy Questionnaire. Chinese Journal of Behavioral Medical Science, 15, 274-276.

Oei, T. P. S., \& Morawska, A. (2004). A Cognitive Model of Binge Drinking: The Influence of Alcohol Expectancies and Drinking Refusal Self-Efficacy. Addictive Behaviors, 29, 159-179. https://doi.org/10.1016/S0306-4603(03)00076-5

Qian, L., Hu, T., Newman, I. M., \& Hou, P. (2008). Study on the Relationship between Cultural Orientation, Alcohol Expectancy, Self-Efficacy, and Drinking Behavior among Senior High School Students in Two Cities in Henan Province. Chinese Journal of Epidemiology, 29, 235-239.

Regan, D., \& Morrison, T. G. (2011). Development and Validation of a Scale Measuring Attitudes toward Non-Drinkers. Substance Use and Misuse, 46, 580-590.

https://doi.org/10.3109/10826084.2010.518748

Santor, D. A., Messervey, D., \& Kusumakar, V. (2000). Measuring Peer Pressure, Popularity, and Conformity in Adolescent Boys and Girls: Predicting School Performance, Sexual Attitudes, and Substance Abuse. Journal of Youth and Adolescence, 29, 163-182. 


\section{https://doi.org/10.1023/A:1005152515264}

Shell, D. F., Newman, I. M., \& Fang, X. (2010). The Influence of Cultural Orientation, Alcohol Expectancies and Self-Efficacy on Adolescent Drinking Behavior in Beijing. Addiction, 105, 1608-1615. https://doi.org/10.1111/j.1360-0443.2010.03006.x

Tang, H., Cai, W., Wang, H., Zhang, Q., Qian, L., Shell, D.F., Newman, I. M., \& Ying, P. (2013). The Association between Cultural Orientation and Drinking Behaviors among University Students in Wuhan, China. PLoS ONE, 8, e54796. https://doi.org/10.1371/journal.pone.0054796

$\mathrm{Tu}, \mathrm{X}$. (2007). On the Teaching Study of Health Education Curriculum of Physical Education Majors. Journal of Jiangxi Institute of Edicatonal, 28, 71-75.

Webb, J. A., \& Baer, P. E. (1995). Influence of Family Disharmony and Parental Alcohol Use on Adolescent Social Skills, Self-Efficacy, and Alcohol Use. Addictive Behaviors, 20, 127-135. https://doi.org/10.1016/0306-4603(94)00054-3

Wu, S., Xu, R., Zhang, J., Wang, Z., Li, K., Run, S., \& Lin, X. (2009). Status of Smoking and Drinking among College Students in Beijing. China Journal School Health, 30, 18-19.

Yeh, M. Y., \& Chen, Y. S. (2007). A Cognitive Model of Drinking among Taiwanese Indigenous Adolescents: The Influence of Alcohol Expectancies and Drinking Refusal Self-Efficacy. Journal of Health Education, 27, 177-194.

Young, R. M., Connor, J. P., Ricciardelli, L. A., \& Saunders, J. B. (2006). The Role of Alcohol Expectancy and Drinking Refusal Self-Efficacy Beliefs in University Student Drinking. Alcohol and Alcoholism, 41, 70-75. https://doi.org/10.1093/alcalc/agh237

Yu, C. Y. (2002). Evaluating Cutoff Criteria of Model Fit Indices for Latent Variable Models with Binary and Continous Outcomes. PhD Thesis, Los Angeles, CA: University of California.

Zhang, J., Merrick, T., Newman, I., \& Qian, L. (2007). Cognition of Social Meaning of Alcohol-Related Flushing among College Students. Chinese Journal of Health Education, 23, 271-274.

Zhang, X., \& Liu, F. (2008). Analysis of the Drinking Status among College Students and the Influencing Factors. Modern Preventive Medicine, 35, 534-536. 